\title{
Editorial \\ Breastmilk: It's Not Just for Breakfast Anymore!
}

\section{Nancy E. Wight, MD, IBCLC}

As perinatal medical professionals, we are rediscovering what nature (and mothers) has known all along — breastmilk is best! We have always agreed that breastmilk and breastfeeding are literally

lifesaving for third-world children. We are now admitting that even in our safe, sanitary, scientific, developed world, breastfeeding is also the normal way to feed babies and has significant advantages for baby, mother, family, and community.1.2

But what about preterm infants, especially the very low birth weight, who did not survive in the past, and would not survive without our technology? Is human milk best for them also? In the not too distant past, all infants, including preterm infants, received human milk. Then came the search for an improved alternative with intense commercial promotion. In our hubris, we have assumed we can do better than "mother nature." Research is now suggesting that human milk may be even more important for compromised and preterm infants than for full-term infants. ${ }^{13-5}$ Despite its "nutritional inadequacies" for preterm infants, human milk is associated with improved neurodevelopment, less necrotizing enterocolitis, less sepsis, and a shorter hospital stay. ${ }^{3}$

Hylander et al., ${ }^{6}$ in a retrospective, observational, cohort study in this issue, add significant information to the "why" of breastmilk for very-low-birth-weight infants. After controlling for confounding predictors of retinopathy of prematurity, human milk feeding independently correlated with a significantly reduced odds of retinopathy of prematurity. Although the numbers were too small to reach statistical significance, results were also suggestive of a doseresponse relationship, with as little as $20 \%$ of total feedings as human milk appearing protective. While research into which human milk factor $(s)$ is responsible for this protective effect may be of value, simply adding a "factor" to artificial milk is unlikely to achieve the same effect. Human milk is a multifactorial, living substance with complex interactions that we are just beginning to unravel. Perhaps the simplest, most cost-effective, and elegant solution is not to genetically engineer bacteria or cows to produce human proteins, but to use the original product!

Marinelli et al., in a prospective, randomized cross-over study of preterm infants, also in this issue, discuss the "how"

Lactation Services, Shar Mary Birch Hospital for Women, 3002 Health Center Drive, San Diego, CA.

Address correspondence and reprint requests to Nancy E. Wight, MD, IBCLC, Lactation Services, Shar Mary Birch Hospital for Women, 3002 Health Center Drive, San Diego, CA 92123. of providing milk to preterm infants. As the oro-motor skills used to suckle at breast and suck at a bottle differ, ${ }^{8}$ and the introduction of a bottle is associated with shorter durations of breastfeeding," there is concern that preterm infants may have difficulty breastfeeding if bottles are used. In most of the world, cups are used as the primary method of supplementing term and preterm infants, but US neonatologists gasp in horror, fearing "aspiration." This study confirms that cup feedings are at least as safe, if not safer, than bottle feedings in this preterm population. During cup feedings, the infants were more physiologically stable, but took less volume, over more time, than with bottle feedings. There is much work to be done to ascertain the safest, most efficient, and yet breastfeedingsupportive method of transitioning preterm infants from gavage to full breastfeeding.

Consensus is building that breastmilk is necessary for preterm infants, although it may not be sufficient for our tiniest charges. Breastfeeding is also more than just nutrition; it is warmth, nurturance, and parenting — an opportunity for the mother of a NICU infant to "lay claim" to her infant. Our NICUs should support mothers seeking to provide breastmilk and breastfeed their infants, and research into the "hows" and "whys" should continue.

\section{References}

1. American Academy of Pediatrics, Workgroup on Breastfeeding. Breastfeeding and the use of human milk. Pediatrics 1999;100(6):1035-9.

2. U.S. Department of Health and Human Services. HHS Blueprint for Action on Breastfeeding. Washington, DC, U.S. Department of Health and Human Services, Office on Women's Health, October 2000 (www.4woman.gov/ breastfeeding/index.htm).

3. Schanler RJ. The use of human milk for premature infants. Pediatr Clin North Am 2001;48(1):207-20.

4. Standing Committee on Nutrition of the British Paediatric Association. Is breastfeeding beneficial in the UK? Arch Dis Child 1994;71:376-80.

5. Lucas A, Morley R, Cole TJ, et al. Breastmilk and subsequent intelligence quotient in children born preterm. Lancet 1992;339:261-4.

6. Hylander MA, Strobino D, Pezzullo, Dhanireddy R. Association of human milk findings with a reduction in retinopathy of prematurity among very low birthweight infants. J Perinatal 2001;21:356-63.

7. Marnelli K, Burke G, Dodd V. A comparison of the safety of cupfeedings and bottlefeedings in premature infants whose mothers intend to breastfeed. J Perinatal 2001;21:350-5.

8. Woolridge MW. The anatomy of infant sucking. Midwifery 1986;2:164-71.

9. World Health Organization. Evidence for the ten steps to succesful breastfeeding. WHO/CHD/98.9, World Health Organization, Geneva, 1998. 